\title{
Research on Inefficient Investment of Listed Companies in China
}

\author{
Dongfang $\mathrm{Qiu}^{1} \&$ Huinan $\mathrm{Wu}^{1}$ \\ ${ }^{1}$ School of Economics and Management, Nanjing University of Aeronautics and Astronautics, Nanjing, China \\ Correspondence: Huinan $\mathrm{Wu}$, School of Economics and Management, Nanjing University of Aeronautics and \\ Astronautics, NO.29, Jiangjun Road, Nanjing, Jiangsu, China. E-mail: Hannah_wu@yeah.net
}

Received: November 22, 2017

Accepted: December 12, 2017

Online Published: December 20, 2017

doi:10.5539/ijbm.v13n1p238

URL: https://doi.org/10.5539/ijbm.v13n1p238

\begin{abstract}
Using samples of A-share listed non-financial companies of 2015, This paper summarizes the research methods of inefficient investment and an effective method is chosen to measure the listed companies in China. The research in this paper shows that: China's listed companies generally exist inefficient investment and there are more companies with less investment, but the scale of inefficient investment is lager in overinvestment. In addition, this paper also provides some suggestions on how to reduce inefficient investment.
\end{abstract}

Keywords: China's A share listed companies, Inefficient investment, Richardson model, Suggestions

\section{Introduction}

Investment activity, as one of the "three carriages" that drive the economic, is an important factor in national economic growth. Since the reform and opening up, China's investment rate has maintained between $30 \%$ and $50 \%$, and has always been in a high proportion in the world. In 2013, President Xi Jinping proposed the "The Belt and Road" strategic blueprint, which has created new opportunities for domestic and foreign investment. The company's investment activities are the important basis for enterprises to achieve the goal of maximizing the value, and also the source guarantee for the survival and further development of enterprises. However, the high investment rate is always accompanied by the low investment efficiency in China. Due to the imperfect capital market and asymmetric information, there are inefficient investment behaviors in many enterprises in China to some extent. Typical inefficient investment behaviors include underinvestment and overinvestment. Underinvestment will hinder the realization of the maximum value of the company, which not only slows down the expansion of the company, but also damages the interests of the investors. Overinvestment will lead to a large amount of capital being wasted in areas of overcapacity. At the same time, it will increase the debt of the company and bring more financial risks and operational risks. Therefore, how to effectively control inefficient investment has become a hotspot to academia and practitioners.

The investment decision of enterprise is the core of financial decision system. Only through investment can enterprises realize the value creation and appreciation of shareholders. This paper intends to analyze the present situation of inefficient investment in China by constructing mathematical model. Furthermore, the reasons of overinvestment and underinvestment are discussed to improve the research framework of the existing investment theory. Through the study of this paper, we provide empirical evidence in China's specific situation, and promote the development of enterprise investment theory research in more complex institutional environment.

\section{Literature Review}

Inefficient investment refers to that managers do not choose investment projects according to the decision criteria of maximizing shareholder value, but aim at maximizing the private benefits of managers. This leads to the inconsistency between the actual investment expenditure and the optimal investment level. The theoretical basis of inefficient investment is principal-agent problem, information asymmetry problem and manager's idiosyncratic problem (Glover B and Levine O,2015). Inefficient investment behavior can be divided into two cases: overinvestment and underinvestment. Over investment refers to the abuse of decision-making power by managers, who invest the idle capital of enterprises into the projects with negative net present value. This will lead to enterprise investment beyond or deviate from the enterprise's own production operation ability and growth opportunities. When internal investors and business decision-makers outside the business cannot get exactly the same information about the existing assets value of the enterprise as well as the future earnings of the project, financing costs will rise due to asymmetric information. This will lead the decision maker to voluntarily 
or passively abandon the investment project with the net present value greater than or equal to zero, which is called underinvestment (Zhang G A and Song X,2009). Therefore, the variables and factors considered by different scholars are different when establishing the measurement model of inefficient investment.

According to the existing literature, there are three main measurement models for inefficient investment:

1). FHP model, which is based on sensitivity of investment and cash sensitivity. The model is used to measure the degree of financial constraints faced by enterprises through the sensitivity of the investment of fixed assets and their free cash flow. From the sensitive point of view, the investment behavior of enterprises with a large number of free cash flow is measured though this model (Frisch, Hasslache \& Pomeau ,1986). Although the FHP model is widely used in academia, the model is not accurate enough to test the efficiency of investment. First of all, it can't measure the efficiency of investment directly. This is because, in practice, it is impossible to distinguish whether the sensitivity of investment expenditure and free cash flow is caused by overinvestment or underinvestment. Secondly2, only financing constraints is considered in the model. The model ignores some other factors, such as the nature of the firm, the size of the company, the industry and so on. In addition, the requirement of the investment opportunity variable $\mathrm{X}$ in the model is that it can predict the free cash flow created by each additional unit investment in the future. However, the weak efficiency of stock market in China makes the stock price unable to effectively play its role in prediction.

2). Vogt model, which is based on the intersection of cash flow and investment opportunity, published by Vogt in 1994. The model tests the cash sensitivity of investment with investment opportunity, cash flow and interaction term, so as to judge whether the enterprise is over investment or under investment. The Tobin Q value is used to measure the investment opportunity. When the investment opportunity is low, the interaction between investment, cash flow and investment opportunity is negative correlation, which means excessive investment. But when the investment opportunity is high, the interaction of investment, cash flow and investment opportunity is positive correlation, then the investment is insufficient. The disadvantage of this method is that it can only judge whether the enterprise is over investment or insufficient investment, but it cannot detect the degree of over investment or underinvestment.

3). Richardson model, which is based on the residual of the investment of the enterprises, published by Richardson in 2006. The model uses residual to measure the degree of inefficient investment, and makes up for the inadequacy of the above two models which cannot quantify the degree of inefficient investment. Richardson uses the accounting method to construct an optimal investment model, including investment opportunities, asset liability ratio, cash flow, company size, company operating years, stock returns, previous year's new investment and other explanatory variables. If the residual term of the model is greater than 0 , it indicates that the enterprise is over invested. If the residual is less than 0 , it means that the enterprise is insufficient investment. Its value indicates the extent of over investment or underinvestment. However, this method does not consider the influence of other factors such as agency conflict and information asymmetry on the investment behavior. And the introduction of the new investment base in the previous year is insufficient, so if the test sample is over investment or insufficient investment, the model will have systematic errors and other problems. Nevertheless, the model is widely used in academic circles because it can make people more intuitive to measure the degree of inefficient investment.

At present, foreign scholars have made fruitful achievements in the study of corporate investment efficiency. However, there is still a dispute over the measurement of investment efficiency, and a unified model has not yet been formed. In recent years, investment efficiency has gradually become the focus of academic circles in China. Domestic scholars have made some preliminary research on the investment behavior of Listed Companies in China by drawing on the research of foreign scholars on the efficiency of investment. However, due to the inconsistency of the actual situation at home and abroad, the investment efficiency theory of foreign scholars is not entirely applicable to the investment efficiency of Listed Companies in China. Generally speaking, there are few literatures about the efficiency of investment in Chinese academia, and the measurement methods and conclusions of inefficient investment are not consistent.

\section{Model Building}

According to the over investment model of Richardson, the total investment of enterprises (I) can be divided into two parts, the capital maintenance expenditure (Imaintenance) and the new project investment (Inew). The new project investment can be decomposed into the expected net present value of the positive expected investment $\mathrm{I}(\mathrm{new}, \mathrm{t})$ *and non-expected investment I(new,t)e. The expected NPV positive investment can be estimated by the model established by Richardson, while the non-expected investment can be judged and measured according to the residual value of the model epsilon. If epsilon $>0$, it shows that the company has over investment, otherwise 
there is insufficient investment. The absolute value of epsilon represents the size of inefficient investment scale.

$$
\begin{gathered}
I_{\text {new }, t}=\alpha+\beta_{1}(v / p)_{t-1}+\beta_{2} \text { Leverage }_{t-1}+\beta_{2} \operatorname{Cash}_{t-1}+\beta_{4} A g e_{t-1}+\beta_{5} \text { Size }_{t-1}+\beta_{6} S R_{t-1}+\beta_{7} I_{\text {new }, t-1}+ \\
\sum \text { Year }+\sum \text { Ind }
\end{gathered}
$$

In the model (1), Richardson defined $\mathrm{I}(\mathrm{new}, \mathrm{t})$ as new investment of this year, $(\mathrm{V} / \mathrm{P})(\mathrm{t}-1)$ as the investment opportunity variables, Lev(t-1) as leverage, leverage on behalf of the company, Cash(t-1) for cash, Age(t-1) and Size $(\mathrm{t}-1)$ as listed age and size of the company for the company, SR(t-1) for stock returns, $\sum$ Year and $\sum$ Ind as year and industry indicators. Chinese scholars have made some adjustments on the basis of the Richardson model. The main thing is to change the investment opportunity variable into the growth opportunity variable, and use the Tobin Q value or the main business income growth rate to measure. According to the Richardson model, we define the new investment (Inew) as the percentage of new investment in total assets in the new year, so that companies with different asset sizes have investment comparability. A model for measuring inefficient investment is proposed as model (2):

$$
I_{\text {new }, t}=\alpha+\beta_{1} Q_{t-1}+\beta_{2} \text { Lev }_{t-1}+\beta_{3} \operatorname{Cash}_{t-1}+\beta_{4} \text { Age }_{t-1}+\beta_{5} E P S_{t-1}+\beta_{6} I_{\text {new }, t-1}+\varepsilon
$$

When the residual value is greater than 0 , the enterprise exceeds the optimal investment scale, namely, excessive investment. The degree of over investment is the magnitude of residual epsilon. Similarly, firms with residuals less than 0 have underinvestment. Based on the regression results of inefficient investment model, we let II= $\mathrm{I}($ new, $\mathrm{t})-\mathrm{I}(\text { new }, \mathrm{t})^{*}=\varepsilon$, Over_It $=\mathrm{I}($ new, $\mathrm{t})-\mathrm{I}(\text { new }, \mathrm{t})^{*}=\varepsilon(\varepsilon>0)$, Under_It $=\mathrm{I}($ new, $\mathrm{t})-\mathrm{I}(\mathrm{new}, \mathrm{t})^{*}=\varepsilon(\varepsilon<0)$ and classify and analyze the investment behavior of enterprises.

Table 1. Variables and Assignments

\begin{tabular}{ll}
\hline Variables & Assignment \\
\hline $\mathrm{I}_{(\text {new }, \mathrm{t})} *$ & New investment / total assets of the enterprise this year \\
$\mathrm{I}_{(\text {new }, \mathrm{t})}$ & The predictive value of the inefficient investment model (2) \\
$\mathrm{II}$ & The residual of the inefficient investment model (2) \\
Over_ $\mathrm{I}_{\mathrm{t}}$ & The residual (epsilon $>0$ ) of the inefficient investment model (2) \\
Under_I $_{\mathrm{t}}$ & The residual (epsilon $<0$ ) of the inefficient investment model (2) \\
$\mathrm{Q}_{(\mathrm{t}-1)}$ & Tobin Q value of last year \\
Lev $_{(\mathrm{t}-1)}$ & Total liabilities at the beginning of a business / initial total assets \\
$\mathrm{Cash}_{(\mathrm{t}-1)}$ & Monetary fund holdings / initial assets at the beginning of the business \\
Age $_{(\mathrm{t}-1)}$ & The number of years listed on the enterprise \\
$\operatorname{Size}_{(\mathrm{t}-1)}$ & The natural logarithm of the total assets at the beginning of a business \\
EPS $_{(\mathrm{t}-1)}$ & Earnings per share for the previous year \\
\hline
\end{tabular}

\section{Results Analysis}

This paper takes A share listed companies as the research sample, and selects data of 2015 as the main object of study. Because the measurement of inefficient investment model involves the related variables of the previous period, the actual observation period of inefficient investment is 2014 and 2015. In addition, the samples are processed as follows.

1) Exclude ST and PT listed companies.

2) In view of the particularity of accounting in financial industry, the listed companies in the financial industry are eliminated.

3) Exclude other companies with related variables missing.

1160 effective observations are finally determined. The data of Listed Companies in this paper are derived from CSMAR and RESSET.

According to the revised inefficient investment measurement model, the investment returns of listed companies are regressed, and the prediction results of the model are calculated. The regression results of the Richardson model are shown in table 2. It can be seen that the company's investment is positively related to investment opportunities, asset liability ratio, earnings per share, the previous year's investment and the size of the company. Corporate investment is negatively related to corporate cash holdings and firm size. This suggests that firms that prefer cash are less invested, and older firms may be more conservative. 
Table 2. Regression result of model

\begin{tabular}{lllllll}
\hline Source & SS & df & MS & & Number of obs & 1160 \\
Model & & 7 & 1406.229 & & F( 7, 1152) & 510.06 \\
Residual & 9843.609 & 7 & 1406.229 & & Prob > F & 0 \\
& 31725.8 & 1152 & 27.539 & & R-squared & 0.537 \\
Total & & & & Adj R-squared & 0.532 \\
\hline I & 41569.41 & 1159 & 35.866 & & Root MSE & 5.248 \\
Q & Coef. & Std.Err & $\mathrm{t}$ & $\mathrm{P}>\mathrm{t}$ & {$[95 \%$ Conf. } & Interval] \\
LEV & 0.570 & 0.612 & 9.300 & 0.003 & 0.449 & 0.690 \\
CASH & 0.477 & 0.874 & 5.500 & 0.005 & 1.239 & 2.194 \\
EPS & -1.073 & 1.436 & -7.500 & 0.004 & 1.747 & 3.892 \\
AGE & 0.236 & 0.263 & 9.000 & 0.003 & 0.281 & 0.753 \\
I(t-1) & -0.136 & 0.035 & -3.880 & 0.008 & -0.205 & -0.067 \\
SIZE & 0.472 & 0.028 & 16.490 & 0.000 & 0.416 & 0.528 \\
cons & 0.569 & 0.144 & 3.930 & 0.008 & 0.285 & 0.853 \\
\hline
\end{tabular}

We subtract the model forecast value from the actual investment amount of the company in 2015 , and get the inefficient investment of the company. There is over investment in the companies whose calculation results are greater than 0 , and the companies with less than 0 have insufficient investment. The listed companies are grouped according to overinvestment and under investment, group descriptive statistics were also conducted. The results show that among the 1160 companies, there are 461 companies with over investment situation, and 699 companies with insufficient investment, which shows that more companies in China have underinvestment, accounting for $60.25 \%$ of the total. This shows that more companies in China have insufficient investment, accounting for $60.25 \%$ of all listed companies.

However, the mean absolute value of the over investment group is 3.889, and the absolute value of the investment group is 2.565. The mean of the two sets of samples shows that the size and severity of over investment of the over invested companies are larger than those of the companies with insufficient investment.

Table 3. Descriptive Statistics Results

\begin{tabular}{llllll}
\hline \multicolumn{2}{l}{$\begin{array}{l}\text { Summary for variables: II } \\
\text { by categories of: GROUP }\end{array}$} & & & \\
\hline GROUP & $\mathrm{N}$ & $\max$ & $\min$ & mean & sd \\
1 & 461.000 & 40.696 & 0.009 & 3.889 & 4.496 \\
2 & 699.000 & -0.001 & -49.157 & -2.565 & 3.944 \\
Total & 1160.000 & 40.696 & -49.157 & 0.000 & 5.232 \\
\hline
\end{tabular}

\section{Conclusion}

Based on the data of domestic listed companies in 2015, this paper analyzes the inefficient investment of listed companies and select reasonable model to measure, and calculate the direction, scale and degree of inefficient investment of domestic listed companies according to the model fitting residuals. And the results were analyzed by descriptive analysis. The results of this study show that China's listed companies generally exist inefficient investment. There are more companies with less investment, which shows that more Chinese enterprises are cautious and conservative in investment. Therefore, these enterprises should pay more attention to enterprise investment and grasp the investment opportunities.

By contrast, the degree of over investment and scale of enterprises with over investment in China is greater than the degree of underinvestment. It shows that although the number of companies with more radical investment in China is relatively small, their investment amount is large. These enterprises should pay more attention to the investment risk and control the investment scale reasonably. Companies should pay attention to internal 
governance and the state and relevant regulatory authorities should introduce and improve relevant policies. On the one hand, enterprises should promote effective investment and avoid idle resources and waste. On the other hand, we should strengthen supervision to prevent investment risks and maintain market stability.

According to the situation of inefficient investment of Chinese listed companies, this paper puts forward the following suggestions:

1) Improve corporate governance laws and regulations. First of all, the company should regulate the stability of equity, so as to give full play to the efficiency of equity governance of listed companies, and improve the efficiency of corporate investment decisions. Secondly, the company should standardize the composition of the board of directors and the working mechanism of the board of directors, and introduce the independent third party evaluation system into the major investment decisions. Thirdly, the state should improve the shareholder litigation system and strengthen the civil liability of directors. In this way, Chinese enterprises will establish a multi-level director responsibility system, which matches civil and criminal responsibilities and distinguishes internal and external director responsibilities.

2) Cultivate competitive market environment for products. The state should reduce industry access restrictions and abolish local or industrial protectionism. The policy should vigorously support the development of non-public enterprises, so as to promote the full competition in the product market, and form a reasonable and orderly market competition environment. Only in this way can enterprises increase investment in R \& D, improve the technical content of products and market competitiveness of products, and reduce inefficient investment.

3) Encourage institutional investors to participate in corporate governance. Compared with the mature market in foreign countries, the participation of Chinese institutional investors in corporate governance is low, and the overall efficiency of corporate governance has not been fully realized. In order to improve the enthusiasm of institutional investors, this paper suggests that the state should implement an elastic stamp tax system. If the stamp tax rate is linked to the stock holding time, the short-term investment behavior of institutional investors can be reduced. In order to curb the short-term investment behavior and encourage the long-term investment behavior of institutional investors, we should increase the short-term transaction cost of institutional investors to increase the short-term transaction cost of institutional investors, so as to expand the internal requirements and consciousness of participating in corporate governance. In addition, in order to alleviate the bottleneck of institutional investors' ability to participate in corporate governance, it is suggested that the institutional investors service companies and institutional investors board should be established in the light of the United States' practice.

4) Strengthen the supervision of information disclosure. The key to improve the quality of information disclosure is to improve the organization system of information disclosure supervision, strengthen supervision, and improve the cost of information disclosure subject violation. High quality information disclosure can alleviate the information asymmetry between the internal controller and the external investors and creditors. It can also reduce agency costs, improve the efficiency of resource allocation in the capital market, and reduce inefficient investment of listed companies.

\section{Acknowledgment}

This paper is one of the periodical achievements of the project for the basic research expenditure of the Central University (No: NR2016014).

\section{References}

Appiah-Adu, K., \& Ranchhod, A. (1998). Market orientation and performance in the biotechnology industry: An exploratory empirical analysis. Technology Analysis \& Strategic Management, 10(2), 197-210.

Bloom, N., Bond, S., Reenen, J. V. (2007). Uncertainty and Investment Dynamics. Review of Economic Studies, 74(2), 391-415.

Chu, E. Y., \& Song, S. I. (2010). Information Asymmetry and Earnings Management: Causes of Inefficient Investment in Malaysia. Social Science Electronic Publishing, 2010.

Duncan, R. B. (1972). Characteristics of organizational environments and perceived environmental uncertainty. Administrative science quarterly, 17(3), 313-327.

Frisch, U., Hasslacher, B., \& Pomeau, Y. (1986). Lattice-Gas Automata for the Navier-Stokes Equation (pp. 1505-1508). 
Glover, B., \& Levine, O. (2015). Uncertainty, Investment, and Managerial Incentives. Journal of Monetary Economics, 69(1),121-137.

Hart, O., \& Zingales, L. (2015). Liquidity and Inefficient Investment. Social Science Electronic Publishing, 13(5), 737-769.

Hu, R., Tian, J., \& Wu, X. (2012). The Empirical Measurement of Enterprise Inefficient Investment Richardson-Based Investment Expectation Model. Communications in Computer \& Information Science, 268, 461-467.

Klein, S., Frazier, G. L., \& Roth, V. J. (1990). A transaction cost analysis model of channel integration in international markets. Journal of Marketing research, 27(2), 196-208.

Lawrence, P. R., \& Lorsch, J. W. (1967). Garrison J S. Organization and environment: Managing differentiation and integration. Boston, MA: Division of Research, Graduate School of Business Administration, Harvard University.

Milliken, F. J. (1987). Three types of perceived uncertainty about the environment: State, effect, and response uncertainty. Academy of Management review, 12(1), 133-143.

Panousi, V., \& Papanikolaou, D. (2012). Investment, Idiosyncratic Risk, and Ownership. The Journal of Finance, 67(3), 1113-1148.

Stokey, N. L. (2016). Wait-and-see: Investment Options Under Policy Uncertainty. Review of Economic Dynamics, 21(3), 246-265.

Zhang, G. A., Song, X. (2009). Measuring Inefficient Investment by Listed Companies in China: Overinvestment or Underinvestment. Accounting Research, 21(5), 69-77.

\section{Copyrights}

Copyright for this article is retained by the author(s), with first publication rights granted to the journal.

This is an open-access article distributed under the terms and conditions of the Creative Commons Attribution license (http://creativecommons.org/licenses/by/4.0/). 